\title{
Cooperative effects of SAHA and VPA on NIS gene expression and proliferation of thyroid cancer cells
}

\author{
Cinzia Puppin ${ }^{1}$, Nadia Passon ${ }^{1}$, Jerome M Hershman ${ }^{2}$, Sebastiano Filetti $^{3}$, Stefania Bulotta ${ }^{4}$, \\ Marilena Celano ${ }^{4}$, Diego Russo ${ }^{4}$ and Giuseppe Damante ${ }^{1,5}$ \\ ${ }^{1}$ Dipartimento di Scienze Mediche e Biologiche, Università di Udine, Piazzale Kolbe 1, 33100 Udine, Italy \\ ${ }^{2}$ Department of Medicine, Veterans Administration Greater Los Angeles Healthcare System, Los Angeles, California, USA \\ ${ }^{3}$ Dipartimento di Medicina Interna e Specialità Mediche, Università di Roma 'Sapienza', Roma, Italy \\ ${ }^{4}$ Dipartimento di Scienze Farmacobiologiche, Università di Catanzaro, Catanzaro, Italy \\ ${ }^{5}$ Azienda Ospedaliero-Universitaria 'S. Maria della Misericordia', Udine, Italy \\ (Correspondence should be addressed to G Damante; Email: giuseppe.damante@ uniud.it)
}

\begin{abstract}
Histone deacetylase inhibitors (HDACi) have shown both anti-proliferative and redifferentiating effects in thyroid cancer cells. Also, they induce the expression of the sodium-iodide symporter gene (NIS (SLC5A5)), a crucial step for radioiodine treatment of thyroid malignancies. Here we investigated the effects of suberoylanilide hydroxamic acid (SAHA) and valproic acid (VPA) on BCPAP and FRO thyroid cancer cells, extending our analysis on the epigenetic mechanisms underlying the NIS gene expression stimulation. In both cell lines we found a cooperative effect of the two compounds on either cell viability and NIS gene expression, resulting in acquired/increased ability to uptake the radioiodine. Such effect was specific since it was not observed for expression of other genes or when SAHA was used in combination with trichostatin A. By using chromatin immunoprecipitation, we investigated epigenetic mechanisms underlying SAHA and VPA effects. Cooperation among the two HDACi occurred on $\mathrm{H} 3$ histone trimethylation at lysine 4 (H3K4me3) and not on histone acetylation. However, effects on H3K4me3 were detected only at the level of NIS Proximal Basal Promoter (NIS-PBP) in FRO cells and only at the level of NIS Upstream Enhancer (NIS-NUE) in BCPAP cells. Our data indicate that epigenetic changes are involved in the synergistic effects of VPA and SAHA on NIS gene expression and that the cellular context modifies effects of $\mathrm{HDACi}$ in terms of $\mathrm{H} 3 \mathrm{~K} 4 \mathrm{me} 3$ target sequence. Investigation of cooperation among different HDACi may provide clues for better defining their mechanism of action in view of their use in thyroid cancer treatment.
\end{abstract}

Journal of Molecular Endocrinology (2012) 48, 217-227

\section{Introduction}

The sodium-iodide symporter (NIS) is a transmembrane protein that mediates active iodide transport across the membrane of thyrocytes, a fundamental step in thyroid hormone synthesis and for adequate radioiodine concentration to detect and destroy recurrent and metastatic thyroid malignancies (De la Vieja et al. 2000, Schlumberger et al. 2007). NIS is encoded by a gene located on chromosome 19p13 consisting of 15 exons and different elements of transcriptional regulation (Riedel et al. 2001). Analyses of human, rat and mouse NIS (SLC5A5) gene have revealed several binding sites for transcription factors relevant for regulation of its expression, located both in the basal promoter and in the NIS upstream enhancer (NUE; Ohno et al. 1999, Schmitt et al. 2001, Taki et al. 2002, Lin et al. 2004, Fenton et al. 2008). Several studies have shown that NIS gene expression is regulated by several factors in a tissue-specific way (Kogai et al. 2006, Hingorani et al. 2010).

In the majority of thyroid cancers, and particularly in metastatic lesions, reduction or abolition of NIS gene expression occurs very often (Lazar et al. 1999, Arturi et al. 2000). Loss of NIS gene expression is related to some oncogene activation (Trapasso et al. 1999, Riesco-Eizaguirre et al. 2009), leading to iodiderefractory recurrent and metastatic disease associated with a worse outcome in the patients (Schlumberger et al. 2007). Attempts to re-introduce the iodine concentration ability in thyroid tumour cells by re-activating the NIS gene expression, therefore, are an important strategy in the field of thyroid cancer research. NIS must be expressed, targeted and retained in the appropriate plasma membrane surface in polarised thyrocytes for active $\mathrm{I}^{-}$transport to occur. In a percentage of thyroid cancers, NIS has been shown to be located intracellularly being unable to 
mediate $\mathrm{I}^{-}$transport (Dohán \& Carrasco 2003). However, expression in the cytosol compartment has been found to be associated with low levels of NIS gene expression (Sodrè et al. 2008). Thus, to understand the molecular mechanism underlying NIS gene expression or silencing is of extreme relevance not only for a deep comprehension of the differentiated phenotype of the thyroid follicular cell, but also for clinical applications.

In recent years, several reports have demonstrated the existence of an epigenetic control of thyroid cell differentiation and proliferation occurring in both normal and transformed thyroid tumour cells: in particular NIS gene expression can be greatly up-regulated by treatment with histone deacetylase inhibitors (HDACi; Kitazono et al. 2001, Furuya et al. 2004, Puppin et al. 2005, Russo et al. 2011). Histone deacetylases (HDACs) are a family of enzymes able to remove acetyl groups from histone tails (Lehrmann et al. 2002). Histone acetylation, which occurs at lysine residues on the amino-terminal tails, neutralises the positive charge of histones and decreases their affinity for DNA. This post-transcriptional modification changes nucleosomal conformation, increases the accessibility of transcription factors to chromatin templates (Struhl 1998) and, therefore, favours active gene expression. HDACs, by removing acetyl groups, induce chromatin compaction and, therefore, favour gene silencing (Gallinari et al. 2007). Over-expression of HDACs and corresponding histone hypoacetylation is a common finding in cancer (Nakagawa et al. 2007, Fritzsche et al. 2008, Weichert et al. 2008a). Moreover, several reports indicate that HDAC over-expression correlates with tumour aggressiveness (Weichert et al. 2008b, Suzuki et al. 2009). Histone hypoacetylation would favour tumour formation and aggressiveness by silencing tumour suppressor genes (Kristensen et al. 2009). It is not surprising, therefore, that compounds able to inhibit HDAC functions have acquired increasing relevance in medical treatment of cancer because of their biological effects such as growth arrest, apoptosis and anti-angiogenesis (Marks \& Xu 2009, Tan et al. 2010). HDACi have been tested in vitro and in vivo against various solid malignancies (Tan et al. 2010); besides their anti-proliferative action in thyroid cancer cells, they have also shown redifferentiation effects (Russo et al. 2011). In this context, attention has been focused on the effects on the NIS gene transcription.

In this work, we investigated the mechanisms controlling the expression of the NIS gene induced by HDACi. Various HDACi agents, differing in their chemical structure, were tested, alone or in combination, against two human thyroid cancer cell lines. A cooperative effect among two different HDACi in terms of both NIS gene expression and cell viability was observed.

\section{Materials and methods}

\section{Cell lines and transfections}

BCPAP cell lines, derived from papillary thyroid carcinoma, and FRO cells, derived from human un-differentiated thyroid carcinoma (Schweppe et al. 2008), were grown in DMEM supplemented with $10 \%$ foetal bovine serum (Invitrogen Corp.). Transfections were performed by Lipofectamine 2000 reagent (Invitrogen Corp.) according to the manufacturer's instructions. In promoter studies, the NIS BP+NUELuc and NIS BP-Luc promoter were transfected in BCPAP and FRO cell lines treated or not with suberoylanilide hydroxamic acid (SAHA) $4 \mu \mathrm{M}$ and/or valproic acid (VPA) $6 \mathrm{mM}$ for $48 \mathrm{~h}$. The transfection efficiency was normalised by cotransfecting the Rous Sarcoma Virus (RSV)-CAT plasmid, which contains the RSV promoter, linked to the chloramphenicol acetyltransferase (CAT) gene. Cells were harvested $48 \mathrm{~h}$ after transfection, and cell extracts were prepared by a standard freeze and thaw procedure. CAT activity was measured by an ELISA method (Amersham). LUC activity was measured by a chemiluminescence procedure (Tell et al. 1998). SAHA was purchased from Cayman Chemical (Ann Arbor, MI, USA); VPA was purchased from USP (Rockville, MD, USA). Unless otherwise specified, other chemicals used were from Sigma.

\section{Evaluation of mRNA levels}

Quantitative PCR analysis of mRNA expression was performed as previously described (Puppin et al. 2005). Briefly, total RNA from cell lines was extracted with RNeasy protect mini kit (Qiagen). One microgram of total RNA was reverse transcribed to single-strand cDNA using random exaprimers and $200 \mathrm{U}$ MMLV reverse transcriptase (Invitrogen Corp.) in a final volume of $20 \mu \mathrm{l}$ at $42{ }^{\circ} \mathrm{C}$ for $50 \mathrm{~min}$ followed by heating at $70{ }^{\circ} \mathrm{C}$ for 15 min. Real-time PCRs were performed using the ABI Prism 7300 Sequence Detection System (Applied Biosystems, Foster City, CA, USA). A $25 \mu \mathrm{l}$ reaction mixture containing $5 \mu \mathrm{l}$ cDNA template, $12.5 \mu \mathrm{l}$ TaqMan Universal PCR master mix (Applied Biosystems) and $1.25 \mu \mathrm{l}$ primer probe mixture was amplified using the following thermal cycler parameters: incubation at $50{ }^{\circ} \mathrm{C}$ for $2 \mathrm{~min}$ and denaturation at $95^{\circ} \mathrm{C}$ for $10 \mathrm{~min}$, then 40 cycles of the amplification step (denaturation at $95^{\circ} \mathrm{C}$ for $15 \mathrm{~s}$ and annealing/extension at $60{ }^{\circ} \mathrm{C}$ for $1 \mathrm{~min})$. The $\Delta C_{\mathrm{t}}$ method, by means of the SDS software (Applied Biosystems), was used to calculate the mRNA levels. Oligonucleotide primers and probes for $N I S$, $P A X 8, A P E / R E F 1$, Periostin and ASF/SF2 were purchased from Applied Biosystems as Assays-on-Demand Gene Expression Products. Oligonucleotide, primers and 
probes for CREM, and the endogenous control $\beta$-actin are described in Table 1.

\section{Chromatin immunoprecipitation assay}

BCPAP and FRO cells (treated or not with HDACi) were cross-linked by the addition of formaldehyde to a final concentration of $1 \%$ for $10 \mathrm{~min}$ before harvesting. Plates were rinsed twice with ice-cold PBS and cells were scraped off the plates, suspended in cell lysis buffer (1\% SDS, $10 \mathrm{mM}$ EDTA, $50 \mathrm{mM}$ Tris-HCl (pH 8.1) and protease inhibitors) and sonicated to generate chromatin to an average length of about 200-600 bp. After centrifugation at 14000 r.p.m. for $10 \mathrm{~min}$ at $4{ }^{\circ} \mathrm{C}$, samples were diluted tenfold with dilution buffer $(0.01 \%$ SDS, $1.1 \%$ Triton X-100, $1.2 \mathrm{mM}$ EDTA, $16 \cdot 7 \mathrm{mM}$ Tris- $\mathrm{HCl}(\mathrm{pH} 8 \cdot 1), 167 \mathrm{mM} \mathrm{NaCl})$. An aliquot (about $10 \%$ of the total) was saved as total input of chromatin and was processed with the eluted immunoprecipitates beginning at the cross-link reversal step. The samples were pre-cleared with $80 \mu \mathrm{l}$ salmon sperm DNA/protein A Agarose beads for $30 \mathrm{~min}$ at $4{ }^{\circ} \mathrm{C}$. Agarose beads were pelleted by centrifugation, the supernatant fraction was collected and immunoprecipitated overnight at $4{ }^{\circ} \mathrm{C}$ with $10 \mu \mathrm{g}$ anti-H3K9K14 acetylated monoclonal antibody (Upstate Biotechnology, Waltham, MA, USA) or H3K4me3 polyclonal rabbit (Active Motif, Carlsbad, CA, USA). As negative control, immunoprecipitation with preimmune serum was performed. Samples and negative controls were incubated with $60 \mu \mathrm{l}$ of salmon sperm DNA/protein A Agarose beads for $1 \mathrm{~h}$ at $4{ }^{\circ} \mathrm{C}$. Agarose beads were pelleted by centrifugation and washed for $5 \mathrm{~min}$ on a rotating platform with $1 \mathrm{ml}$ of each buffer: low salt, high salt, LiCl wash buffer and TE buffer. Immunocomplexes were eluted with elution buffer (1\% SDS, $50 \mathrm{mM} \mathrm{NaHCO} 3$ ) and cross-links were reverted by incubation at $65{ }^{\circ} \mathrm{C}$ for $4 \mathrm{~h}$. Samples were added with proteinase $\mathrm{K}$, Tris- $\mathrm{HCl}(\mathrm{pH} 6.5)$ and EDTA $0.5 \mathrm{M}$ and incubated for $1 \mathrm{~h}$ at $45^{\circ} \mathrm{C}$. DNA was purified with phenol/chloroform and used as template in a quantitative PCR to detect the presence of NIS proximal basal promoter (NIS-PBP), NIS distal basal promoter (NIS-DBP), NIS-NUE and NIS intron 8 (NISINT) elements (Table 1). After quantitative PCRs, the acetylated or methylated H3 levels were determined by dividing the signal obtained after immunoprecipitation by the signal before immunoprecipitation (input). Results of chromatin immunoprecipitation (ChIP) assays are expressed as fraction of the input.

\section{Viability assay and ${ }^{125}$ I accumulation}

Three hours before the end of treatment with HDACi, a solution containing MTT $4 \mathrm{mg} / \mathrm{ml}$ in PBS was added to
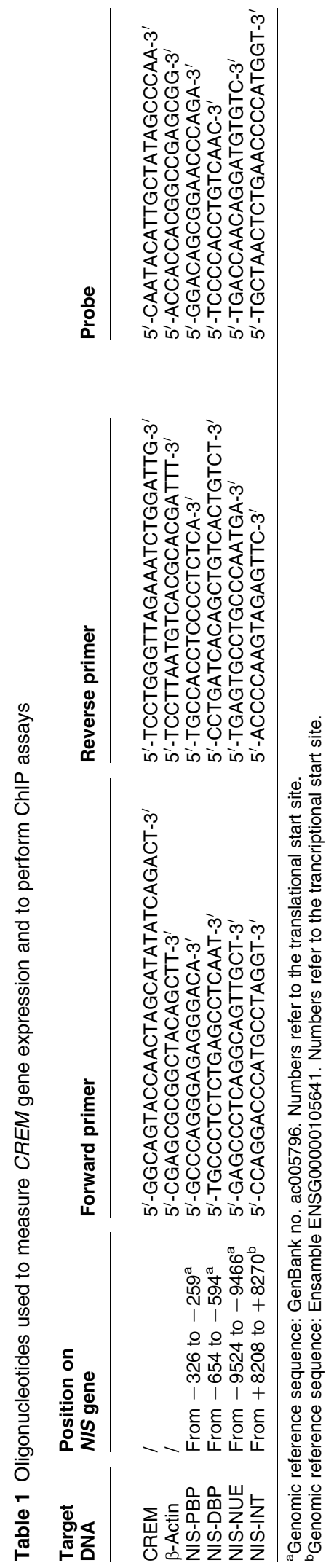

www.endocrinology-journals.org 
$10 \%$ in the culture medium. After $3 \mathrm{~h}$ the medium was removed and cells were lysed with DMSO. The adsorbance of the samples was analysed at a wavelength of $540 \mathrm{~nm}$ with background subtraction at $690 \mathrm{~nm}$. All experimental points were run in quadruplicate.

To measure ${ }^{125} \mathrm{I}$ accumulation, cells were split and seeded into six-well plates and, after aspiration of the culture medium, they were washed with $1 \mathrm{ml}$ Hank's balanced salt solution (HBSS; Life Technologies S.r.l.) supplemented with HEPES (10 mM, pH 7·3). Iodide accumulation was initiated by adding to each well $500 \mu \mathrm{l}$ buffered HBSS containing $10 \mu \mathrm{Ci}$ carrier-free NaI (Amersham Pharmacia Biotech) and $0.1 \mathrm{mM} \mathrm{NaI}$ (Sigma-Aldrich S.r.l) to obtain a specific activity of $200 \mathrm{mCi} / \mathrm{mmol}$. In half of the wells, used as controls for NIS-mediated uptake, this assay buffer also contained $10 \mathrm{mM} \mathrm{KClO}_{4}$, which is a specific NIS inhibitor. After $30 \mathrm{~min}$ at $37^{\circ} \mathrm{C}$, the radioactive solution was removed, and cells were washed with $1 \mathrm{ml}$ ice-cold HBSS. Then, $1 \mathrm{ml}$ of $95 \%$ ethanol was placed in each well and left for 20 min before being transferred into vials for counting with a gamma counter. Iodide uptake was expressed as picomoles per microgram of cellular DNA, which was measured as previously described (Arturi et al. 2005).

\section{Results}

\section{Cooperative effects of SAHA and VPA on NIS gene expression}

We and others have previously shown that TSA and sodium butyrate $(\mathrm{NaB})$ induce NIS gene expression in thyroid tumour cell lines (Puppin et al. 2005). However, both TSA and $\mathrm{NaB}$ are not of common use in therapy; therefore, we tested whether HDACi are widely utilised as anti-cancer drugs such as SAHA and VPA had effects on NIS gene expression in human thyroid cancer cell lines. BCPAP (derived from a thyroid papillary carcinoma) and FRO (derived from an anaplastic thyroid carcinoma) were utilised. First, we evaluated the effects on cell viability, testing several doses of SAHA and VPA at various incubation times. After $48 \mathrm{~h}$ treatment, the minimal doses of SAHA and VPA inducing significant decrease of cell viability in both cell lines were $4 \mu \mathrm{M}$ and $6 \mathrm{mM}$ respectively (Fig. 1 and data not shown). Thus, in all subsequent experiments these doses and this time of treatment were used.

Effects of SAHA and VPA on NIS gene expression were next evaluated by quantitative RT-PCR. As shown in Fig. 2, for all conditions tested, HDACi effects on BCPAP cells were much higher than in FRO cells (note the different scales of NIS mRNA levels in the two graphics). In addition, in both cell lines, SAHA exerted stronger effects than VPA. When cell lines were treated with SAHA and VPA together, the increase of NIS gene
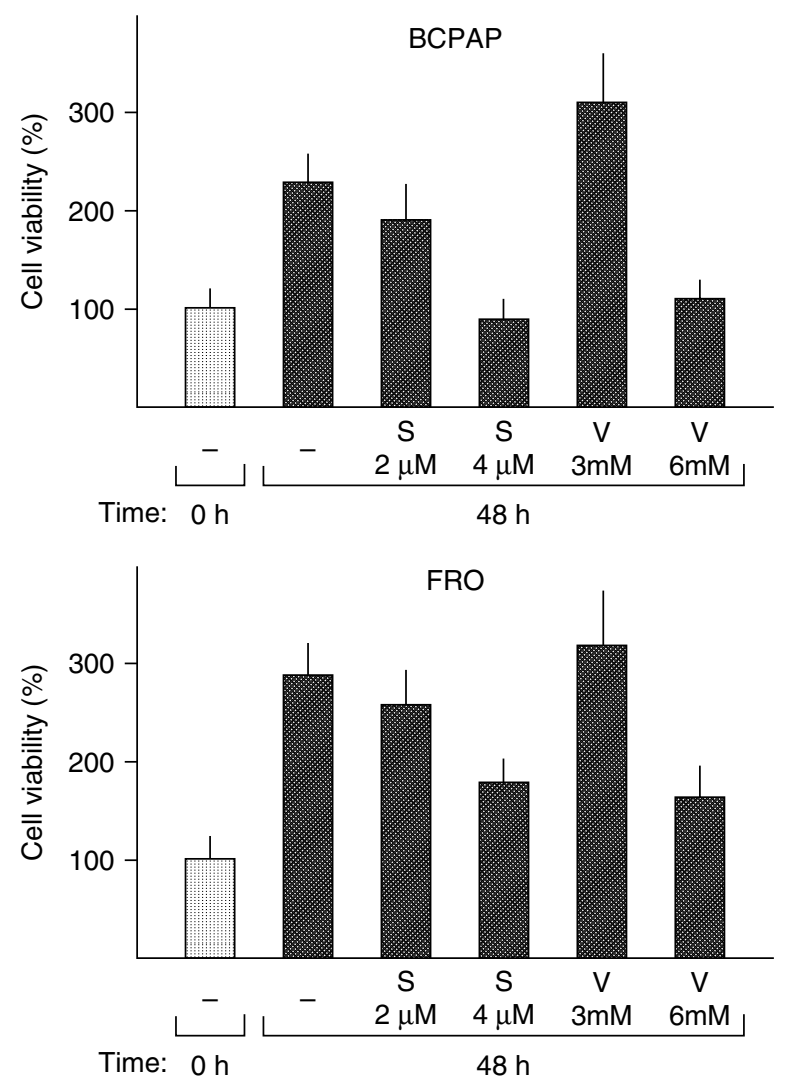

Figure 1 Effect of SAHA and VPA on viability of thyroid tumour cell lines. BCPAP and FRO cells were plated in 96 multi-wells at a concentration of 4500 cells/well. After $24 \mathrm{~h}$, viable cell number of time 0 was evaluated. At the same time, in the remaining wells, the various compounds were added and cultures were continued for additional $48 \mathrm{~h}$. Cells were then lysed with DMSO and the absorbances of the samples were measured at the wavelength of $540 \mathrm{~mm}$. In all wells $3 \mathrm{~h}$ before cell lysis $10 \%$ MTT solution was added to the culture medium. Each bar represents the mean value \pm S.D. of quadruplicate determinations. Top panel, BCPAP cells; bottom panel, FRO cells. In each panel $S$ and $V$ indicate SAHA and VPA respectively.

expression was much higher than when the two HDACi were separately administered. We name this effect as cooperation between SAHA and VPA. These two HDACi have completely different chemical structures: SAHA is a derivative of hydroxamic acid while VPA is a short-chain fatty acid. Thus, cooperation could be due to partially different mechanisms of action. This hypothesis is corroborated by the finding that when SAHA is administered with another derivative of hydroxamic acid (trichostatin A), no cooperation was observed (Fig. 2).

Since an increase in NIS mRNA or protein levels does not always result in an increase of iodine uptake (Dohán et al. 2001), we then evaluated whether HDACi effects on NIS mRNA resulted in modification of NIS function. As shown in Fig. 3, treatment with either SAHA or VPA determined a small increase of 

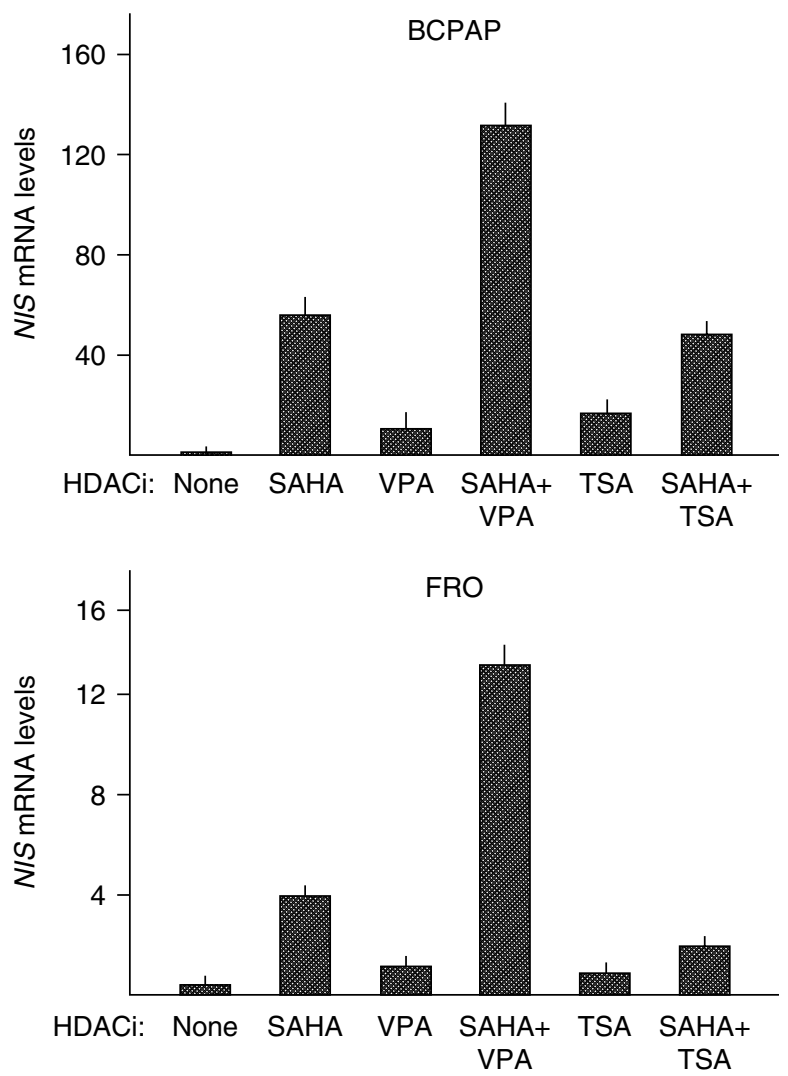

Figure 2 Effect of different HDACi on NIS mRNA levels in thyroid tumour cell lines. BCPAP and FRO cells were treated with the indicated compounds (SAHA $4 \mu \mathrm{M}$ and VPA $6 \mathrm{mM}$ ) for $48 \mathrm{~h}$. At the end, cells were scraped and RNA was extracted by the RNeasy mini kit (Qiagen). The amount of RNA was evaluated by the Nanodrop spectrophotometer (ThermoScientific, Waltham, MA, USA). Then, starting from $1 \mu \mathrm{g}$ of RNA, cDNA was synthesised by using the MMLV reverse transcriptase (Invitrogen). NIS mRNA levels were then evaluated by quantitative PCR as described in Materials and methods. Top panel, BCPAP cells; bottom panel, FRO cells. In each panel NIS mRNA levels are expressed as multiple of those detected in untreated BCPAP cells, considered arbitrarily as 1 . Each bar represents the mean value \pm s.D. of three independent determinations.

${ }^{125}$ I accumulation in BCPAP and FRO cells. However, when SAHA and VPA were added together, a higher increase of ${ }^{125} \mathrm{I}$ accumulation was detected both in BCPAP cells (2·5-fold) and in FRO cells (sixfold).

In order to test whether the cooperation between SAHA and VPA is specific for NIS gene, effects of HDACi on other genes were investigated. Transcript levels of PAX8, TTF-1 (NKX2-1), TTF-2 (FOXE1) CREM, TSHR, TPO, APE-REF1 (APEX1), ASF/SF2 (SRSF1) and Periostin upon HDACi treatment of BCPAP and FRO cells were investigated. PAX8 and CREM are involved in the activation of NIS gene expression (Ohno et al. 1999, Fenton $e t$ al. 2008). As shown in Fig. 4, heterogeneous results were obtained depending on the HDACi agent, the target gene analysed and the cell line. However, except for the CREM gene in FRO cells, no cooperation was detectable between SAHA and VPA for all the other transcripts examined. In the case of TPO, in all tested conditions absence of NIS mRNA was found (data not shown). Thus, the cooperative effect of the two HDACi on NIS gene expression is specific. Moreover, HDACi may exert different effects in the two different cell lines, depending on the gene context.

In addition to gene expression, we tested whether SAHA and VPA cooperated in terms of cell viability. Data are shown in Fig. 5. In BCPAP cells, after $24 \mathrm{~h}$ proliferation, single SAHA and VPA treatment shows no significant effect compared with untreated cells; however, when the two HDACi are used together, a significant decrease of cell viability is observed. Such a cooperative effect is detected also after $48 \mathrm{~h}$ proliferation. In the case of FRO cells, after $48 \mathrm{~h}$, single SAHA or VPA treatment reduces cell growth. However, only when the two HDACi are used together, the number of viable cells is reduced compared to time 0 . These data clearly indicate that when SAHA and VPA are used together, cooperation is detected both on cell viability and NIS gene expression.

\section{Mechanisms of cooperation}

HDACi act primarily on gene transcription. Thus, to investigate the mechanism underlying cooperation between SAHA and VPA on NIS gene expression, the effects of the two HDACi were evaluated on the activity of transcriptional regulatory elements of NIS gene. A transfection approach was utilised. Plasmids in which transcription of the reporter $L U C$ gene is controlled either by NIS-BP or by NIS-BP+ NUE (Taki et al. 2002) were transfected into BCPAP and FRO cells, which were

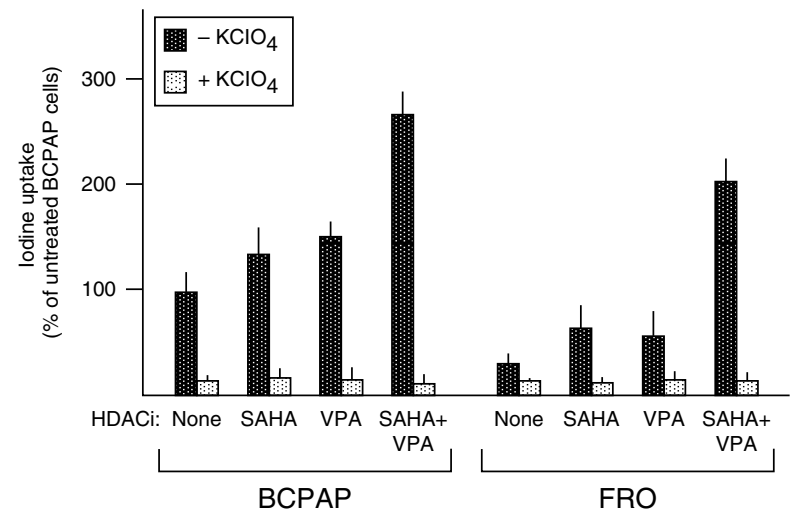

Figure 3 Effect of SAHA and VPA on ${ }^{125}$ accumulation. BCPAP and FRO cells were treated with the indicated compounds (SAHA $4 \mu \mathrm{M}$ and VPA $6 \mathrm{mM}$ ) for $48 \mathrm{~h}$, then ${ }^{125} \mathrm{I}$ accumulation was measured as described in Materials and methods. Results are expressed as percentage of values found in untreated BCPAP cells. Each bar represents the mean value \pm s.D. of three independent determinations. 

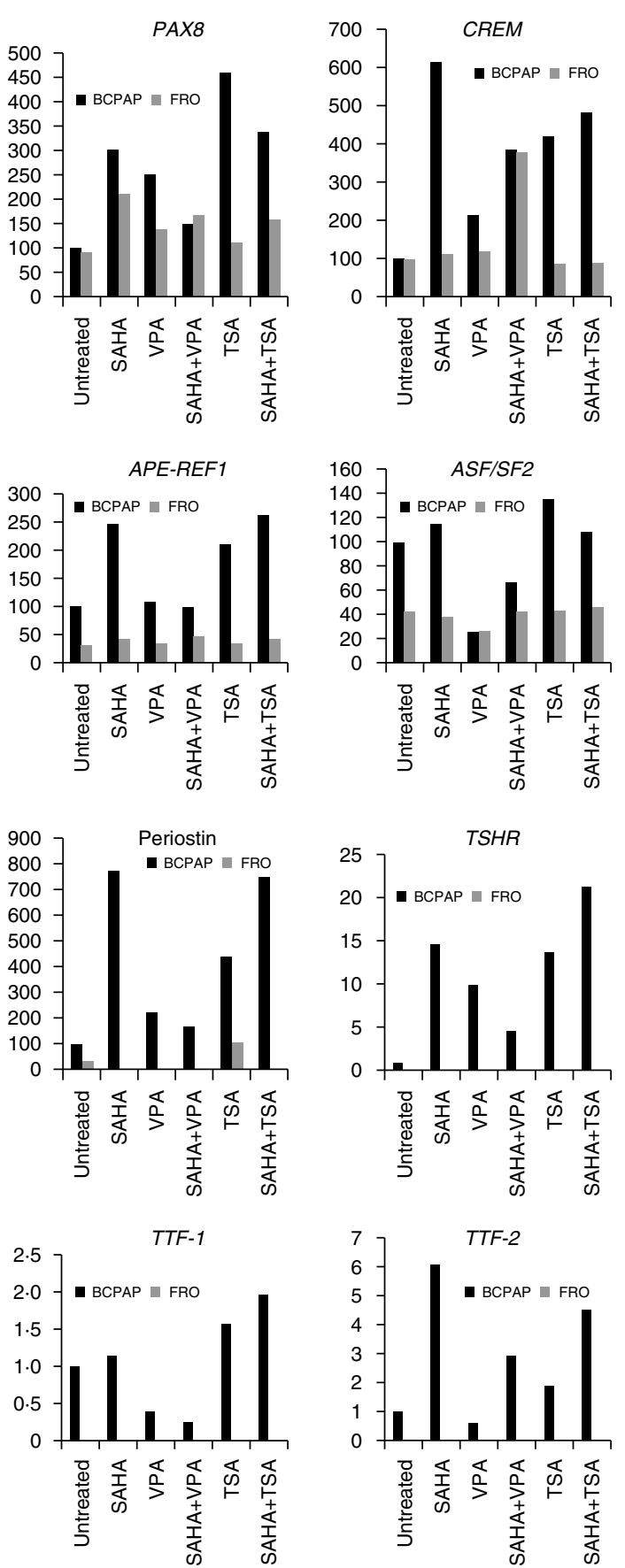

Figure 4 Effect of SAHA and VPA on mRNA levels of various genes in thyroid tumour cell lines. BCPAP and FRO cells were treated with the indicated compounds (SAHA $4 \mu \mathrm{M}$ and VPA $6 \mathrm{mM}$ ) for $48 \mathrm{~h}$. RNA was extracted, quantified and reverse-transcribed as indicated in Fig. 2 legend. mRNA levels of $P A X 8, C R E M, A P E-R E F 1$, ASF/SF2, Periostin, TSHR, TTF-1 and TTF-2genes were evaluated as described in Materials and methods. In each graph mRNA levels are expressed as multiple of those detected in untreated BCPAP cells, considered arbitrarily as 100 . Each bar represents the mean value of three independent determinations. For all conditions, S.D. was not above $15 \%$ of the mean values. subsequently treated with SAHA and VPA, alone and in combination. As shown in Fig. 6 , in both cell lines single use of SAHA or VPA increased the transcriptional activity of both NIS-BP and NIS-BP + NUE more than the combination SAHA+VPA. In both cell lines, the effects of the two HDACi are more evident on NIS-BP than NIS-BP + NUE transfected cells. These data indicate that transfected regulatory elements of NIS gene do not reproduce the cooperative effect between SAHA and VPA observed on NIS mRNA levels.

In order to explore whether cooperation between SAHA and VPA could be explained by changes in the regulation on NIS endogenous gene expression, we focused on epigenetics. In a first set of experiments, histone acetylation was investigated. This posttranslational modification is strongly associated with activation of gene transcription (Shahbazian \& Grunstein 2007). We used an antibody that specifically recognises acetylated lysines at positions 9 and 14 of histone H3 (H3K9K14ac) to perform a ChIP assay. In fact, acetylation of K9 and K14 of histone H3 bound to transcriptional regulatory sequences is a widely adopted mark of gene activation (Rando 2007). Both the basal promoter and the NUE were investigated, as well as intron 8 of the NIS gene. The NIS basal promoter was investigated at two regions: NIS-PBP and NIS-DBP, located at bases -326 to -259 and -654 to -594 from the translational start site respectively. Results are shown in Fig. 7. Basal levels of H3K9K14ac for NIS-PBP, NIS-DBP and NIS-NUE in BCPAP cells were much lower than those detected in FRO cells. Therefore, basal levels of H3K9K14ac in the transcriptional regulatory elements of NIS gene do not correlate with basal levels of NIS mRNA, which in BCPAP cells are threefold higher than in FRO cells. In both cell lines, levels of H3K9K14ac at intron 8 were lower than those detected in transcriptional regulatory elements. In both cell lines, for all four investigated regions, SAHA induced higher levels of H3K9K14ac than VPA. For both HDACi, the extent of H3K9K14ac increase was higher in BCPAP cells than in FRO cells; this behaviour correlates with the extent of NIS mRNA levels increase (see Fig. 2). When the SAHA and VPA were used together in BCPAP cells, acetylation levels at the transcriptional regulatory elements were intermediate compared to those detected when single HDACi was used. In FRO cells, the combined use of SAHA and VPA induced a great reduction of H3K9K14ac with respect to SAHA at the level of all four investigated regions. It is evident that in both cell lines, SAHA and VPA show no cooperation in terms of modification of H3K9K14ac levels. Therefore, the synergistic action of the two HDACi on NIS mRNA levels is not related to histone $\mathrm{H} 3$ acetylation levels.

A different epigenetic modification strictly associated with transcriptional activation is the H3 histone trimethylation at lysine 4 (H3K4me3; 

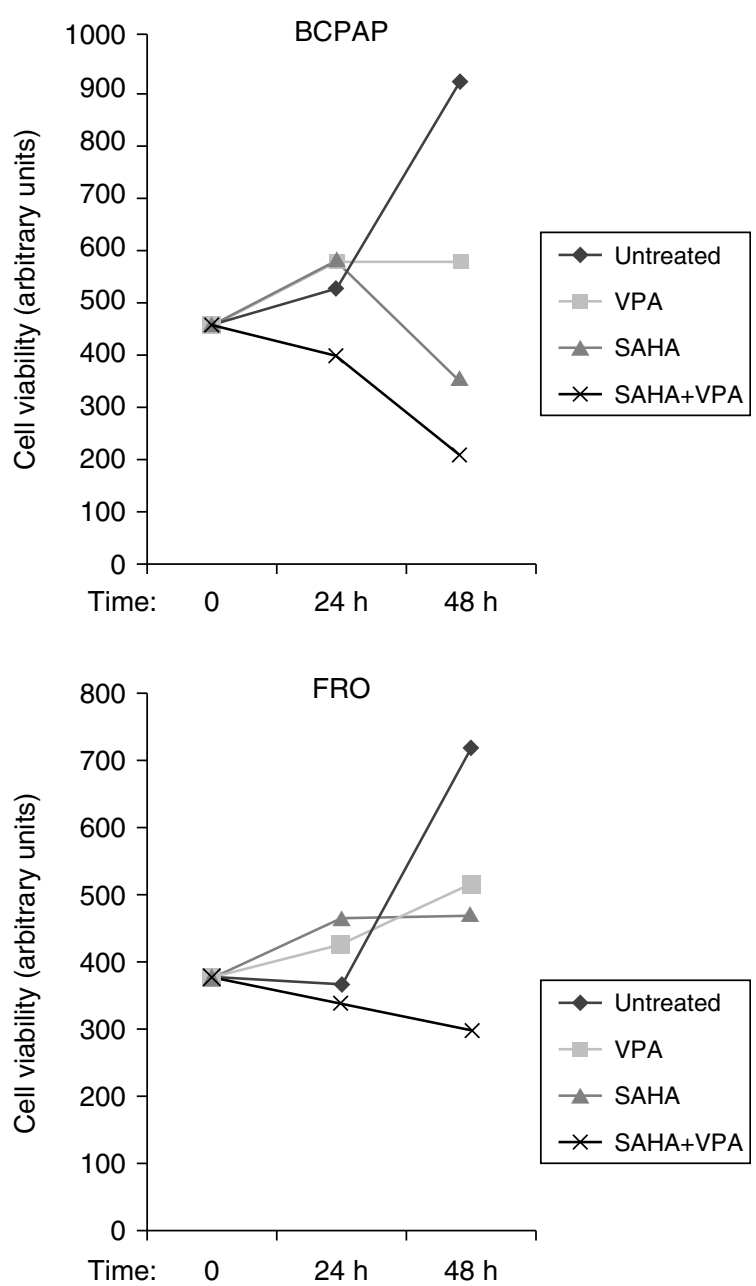

Figure 5 Co-operative effect of SAHA and VPA on viability of thyroid tumour cell lines. Cell viability of BCPAP and FRO cells was evaluated as described in Fig. 1 legend. The MTT assay was performed 24 and $48 \mathrm{~h}$ after the beginning of treatment. Top panel, BCPAP cells; bottom panel, FRO cells. In both panels, symbols indicate mean values of quadruplicate determinations. For all conditions, S.D. was not above $10 \%$ of the mean values.

Santos-Rosa et al. 2002). Since it is known that HDACi are able to increase this epigenetic mark (Nightingale et al. 2007), in a second set of experiments, effects of SAHA and VPA alone and in combination on the levels of H3K4me3 in NIS-PBP, NIS-DBP, NIS-NUE and NIS-INT regions were evaluated by ChIP. As shown in Fig. 8, in BCPAP cell line, basal values of H3K4me3 levels for NIS-PBP, NIS-DBP or NIS-NUE were higher than in FRO cells. In both cell lines H3K4me3 levels were much lower in the intron 8 (NIS-INT) than in the transcriptional regulatory regions. In these regions, increase of H3K4me3 levels upon single HDACi treatment was observed in both BCPAP and FRO cell lines, with VPA effects higher than those elicited by SAHA. However, while in BCPAP cells, VPA induced effects higher than SAHA in all three investigated regions, in FRO cells increase in H3K4me3 levels upon VPA treatment was detected only in NIS-PBP and NIS-DBP. When SAHA and VPA were used together, different results were obtained in the two cell lines. In BCPAP cells, only the NIS-NUE element showed H3K4me3 levels significantly higher compared to those detected when either HDACi was used in single. In FRO cells, instead, both the NIS-PBP and the NIS-INT element showed H3K4me3 levels significantly higher compared to detected when either HDACi was used in single. Thus, in both cell lines cooperation between SAHA and VPA was observed in terms of H3K4me3. However, considering transcriptional regulatory elements only, while in BCPAP cells cooperation is exerted on NIS-NUE, in FRO cells the cooperative effect is detected on NIS-PBP. These data suggest, therefore, that the synergistic effects of SAHA and VPA on NIS mRNA levels would be due to changes in H3K4me3 levels. Moreover, depending on the cell line, such a cooperation is exerted on different transcription regulatory sequences of the NIS gene.

\section{Discussion}

Epigenetic alterations are one of the novel promising targets for the treatment of various malignancies. In this regard, HDACi are currently tested as single agents or in combination with other anti-cancer drugs in various ongoing clinical trials. Indeed, many reports have described the existence of a cooperation among HDACi and other compounds in modifying gene expression with benefits for anti-cancer therapy (Nightingale et al. 2007, Marks \& Xu 2009). In different thyroid cancer cell lines, for example, it has been shown that SAHA synergises with compounds able to inhibit MAPK, PI3K/Akt and mTOR pathways (Hou et al. 2010). However, to our knowledge, no cooperation among old-generation HDACi has so far been reported. SAHA and VPA are two HDACi with different chemical structures, the first being a derivative of hydroxamic acid and the second a short-chain fatty acid (Batty et al. 2009). Though different in chemical structure, each compound is considered a wide-spectrum HDACi, with no selectivity for the various HDACs. However, differences in the action between SAHA and VPA have been described. For example SAHA, but not VPA, is able to inhibit class IIb HDACs (HDAC6 and HDAC10) (Duenas-Gonzalez et al. 2008, Marks \& Xu 2009). In contrast, VPA, but not SAHA, induces proteosomal degradation of HDAC2 (Krämer et al. 2003). In addition to its inhibition of HDACs, VPA has been shown to activate the glycogen synthase kinase-3 (GSK-3)/ $\beta$-catenin and ERK pathways (Rosenberg 2007). In a rodent model of traumatic brain injury, VPA, but not SAHA, provides neuroprotection and 

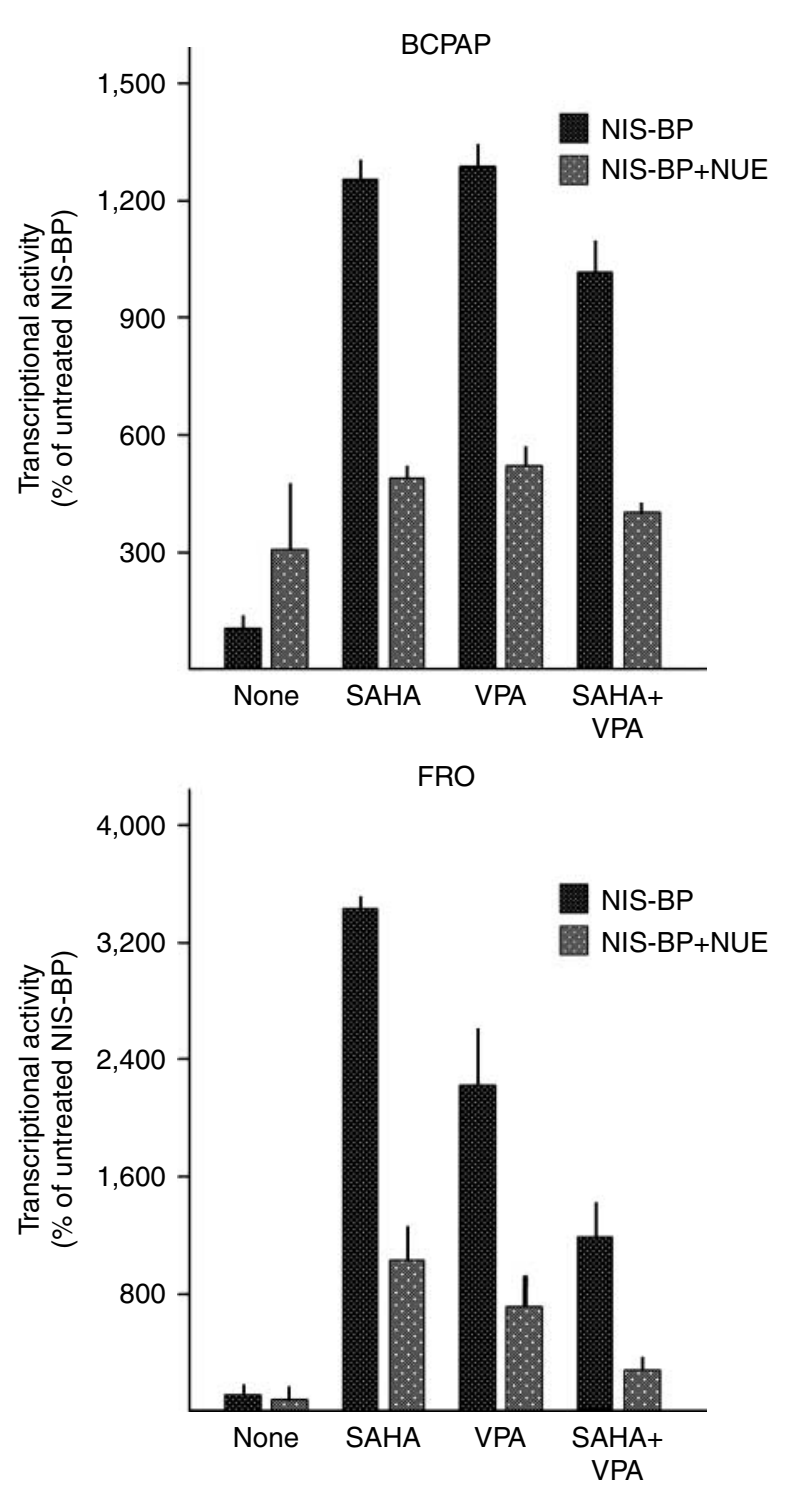

Figure 6 Effect of SAHA and VPA on transcriptional regulatory elements of NIS gene. Transcriptional activity of NIS-BP and NIS-BP + NUE linked to the $L U C$ gene was evaluated in both BCPAP and FRO cell lines as described in Materials and methods. Top panel, transcriptional activities detected in BCPAP cells; bottom panel, transcriptional activities detected in FRO cells. In each panel transcriptional activity is expressed as percentage of that of NIS-BP in untreated cells. Each bar represents the mean value \pm s.D. of three independent transfections.

improves cognitive functions (Dash et al. 2010). In contrast, SAHA, but not VPA, protects V79 cells against $\mathrm{H}_{2} \mathrm{O}_{2}$-induced killing (Samuni et al. 2009).

The notion that distinct HDACi may display major differences in biological response has been reinforced very recently (Chang et al. 2012). In that research, by using different cancer cell lines, it was shown that HDACi trichostatin A and depsipeptide demonstrate distinct phenotypes in the inhibition of cell viability as well as various molecular parameters.

SAHA and VPA, as well as depsipeptide and trichostatin A, have been extensively investigated on thyroid cancer cells showing both anti-proliferative and redifferentiating effects. In particular, an increase of radioiodine uptake, due to restored NIS protein expression mainly detected at mRNA levels, has been described in several pre-clinical models of cells treated with HDACi (Russo et al. 2011). In this study we demonstrate, for the first time, the cooperativity between two different HDACi in increasing NIS mRNA levels. This cooperative effect of SAHA and VPA is gene and cell-type specific. In fact, when expression of other genes was evaluated, only one of them (CREM) was activated in a cooperative way and in only one cell line (FRO cells). Cooperation between SAHA and VPA in FRO cells on CREM expression, however, does not result in a cooperation on the transcriptional activity of NIS promoter and NUE (see Fig. 6). This result is apparently puzzling since in nontumourigenic thyroid cells CREM acts as an NUE activator (Fenton et al. 2008). However, we have very recently shown that in tumourigenic thyroid cell lines (such as FRO) CREM acts as a repressor of NUE (Passon and Damante, 2011 unpublished data).

Since there are differences in the chemical structure and some mechanisms of action between SAHA and VPA, our findings were not completely unexpected. Consistent with the notion that SAHA and VPA cooperate because of their structural differences and, therefore, partial different biochemical effects, we found that SAHA and TSA, both compounds being derivative of the hydroxamic acid, do not show cooperative effects on NIS gene expression. Interestingly, the cooperative effect between SAHA and VPA is also observed in terms of cell viability. Thus, our findings suggest that cocktails with different HDACi, never tested to our knowledge even in pre-clinical models of human tumours, could be effective for cancer treatment. It would result in a decrease of the effective doses, with a potential reduction or abolishment of toxicity.

Moreover, our findings provide a step forward for understanding the molecular events underlying the cooperation of SAHA and VPA on NIS gene expression. Transfection experiments indicate that cooperation between the two HDACi is not due to modifications of trans-acting factors interacting with transcriptional regulatory sequences of the NIS gene. If modifications of factors acting in trans cannot explain cooperation among the two compounds, such effect could be related to modifications of cis elements, which are not reproduced by the transfected construct. Exploration of epigenetic modifications, in particular histone acetylation and methylation, provided a possible explanation of this phenomenon. We investigated 

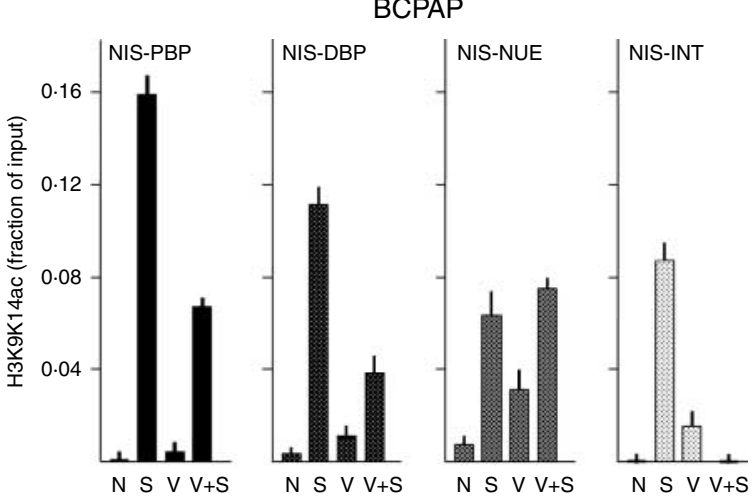

FRO
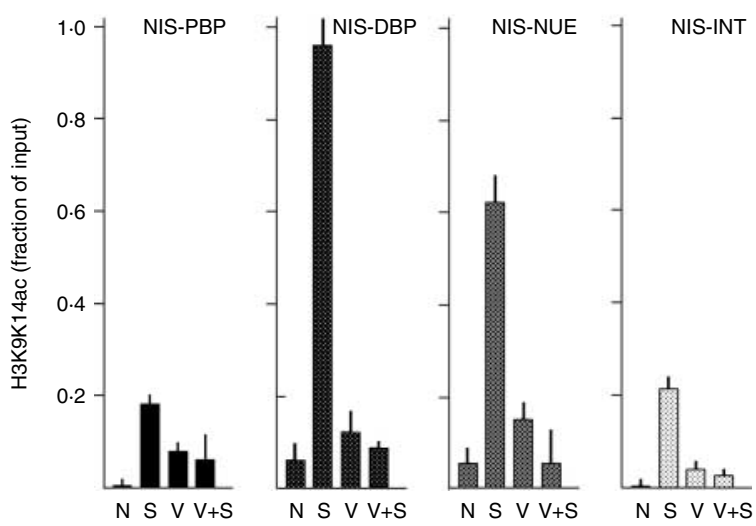

Figure 7 Effect of SAHA and VPA on levels of H3K9K14ac at NIS-PBP, NIS-DBP, NIS-NUE and NIS-INT sequences in thyroid tumour cell lines. BCPAP and FRO cells were treated with the indicated compounds (SAHA $4 \mu \mathrm{M}$ and VPA $6 \mathrm{mM}$ ) and levels of $\mathrm{H} 3 \mathrm{~K} 9 \mathrm{~K} 14 \mathrm{ac}$ were evaluated by ChIP as described in the Materials and methods. Top and bottom panels show H3K9K14ac levels in BCPAP and FRO cells respectively. In both panels levels of H3K9K14ac are expressed as fraction of the input (material before immunoprecipitation). Each bar represents the mean value \pm s.D. of a triplicate measure.

acetylation at lysines 9 and 14 as well as H3K4me3. All these modifications are associated with transcriptional activation (Santos-Rosa et al. 2002, Rando 2007). Our data demonstrate that SAHA and VPA do not show cooperation in terms of H3K9K14ac levels. In contrast, our data indicate that HDACi cooperate in increasing H3K4me3 levels. Such an effect was described in the past in other experimental models and related to the effect of HDAC inhibition on histone methyltransferases and demethylases (Nightingale et al. 2007, Huang et al. 2011). An interesting novelty of our data is the finding that cooperation of SAHA and VPA in increasing H3K4me3 levels occurs on distinct transcriptional regulatory elements (NIS-PBP and NIS-NUE), depending on the cell line. We found, in fact, that this kind of cooperative effects among SAHA and VPA is observed only in NIS-NUE in BCPAP cells and only in NIS-PBP in FRO cells. It appears, therefore, that enzymes controlling the trimethylation status of H3K4 act in a sequence-specific manner. This sequence specificity, however, is coupled with structure of chromosomal context because cooperation between SAHA and VPA was not detected in the episomal context. This model is in complete agreement with a mechanism recently proposed on the methylation of H3K4 (Ruthenburg et al. 2007), suggesting that complexes of chromatin-associated proteins could be recruited to gene targets through multiple weak or transient interactions (including sequence-specific DNA binding) that together produce specificity and stable binding. According to our data, in BCPAP and FRO cells these mechanisms act in different ways, resulting in increased levels of H3K4me3 in distinct transcriptional regulatory elements of NIS gene.

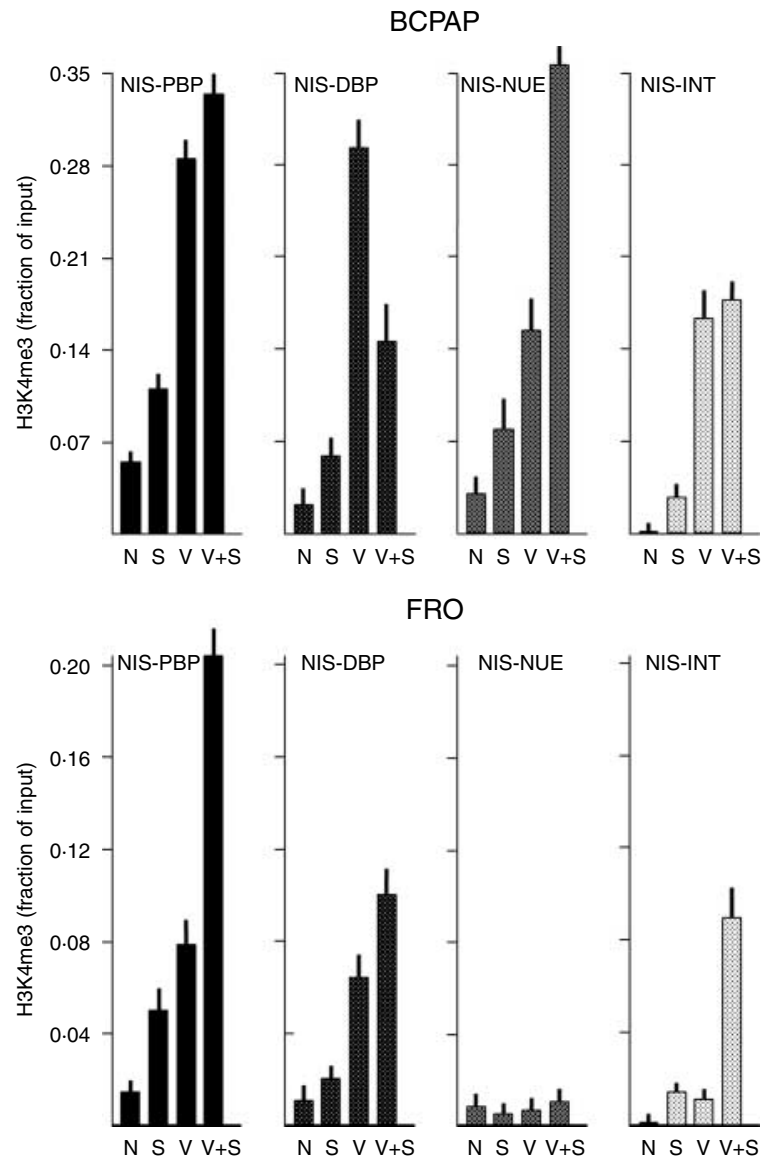

Figure 8 Effect of SAHA and VPA on levels of H3K4me3 at NIS-PBP, NIS-DBP, NIS-NUE and NIS-INT sequences in thyroid tumour cell lines. BCPAP and FRO cells were treated with the indicated compounds and levels of $\mathrm{H} 3 \mathrm{~K} 4 \mathrm{me} 3$ were evaluated by ChIP as described in the Materials and methods. Top and bottom panels show H3K4me3 levels in BCPAP and FRO cells respectively. In both panels levels of $\mathrm{H} 3 \mathrm{~K} 4 \mathrm{me} 3$ are expressed as fraction of the input (material before immunoprecipitation). Each bar represents the mean value \pm s.D. of a triplicate measure. 
In conclusion, we have demonstrated a cooperative action of two different HDACi (which a low selectivity for distinct HDACs) on expression of NIS gene and proliferation of thyroid tumour cells. Also the epigenetic changes at the basis of such a cooperation have been described. More selective HDACi are in development and are going to be used as anti-cancer drugs (Balasubramanian et al. 2009). Because of their high selectivity, these new compounds may display reduced overlap in mechanism of action, as suggested by the present finding. Moreover, in agreement with this hypothesis, very recent work has shown cooperation among selective inhibitors of class I and II HDACs in blocking osteoclast activity (Cantley et al. 2011). Thus, definition of the molecular mechanism underlying cooperation between these new drugs may open new frontiers in the field of thyroid cancer treatment.

\section{Declaration of interest}

The authors declare that there is no conflict of interest that could be prejudicing the impartiality of the research reported.

\section{Funding}

This work was supported by grants to G D from Associazione Italiana per la Ricerca sul Cancro (AIRC) (grant number IG 10296) and MIUR (PRIN grant number 20093WAPIK_003).

\section{References}

Arturi F, Russo D, Giuffrida D, Schlumberger M \& Filetti S 2000 Sodium-iodide symporter (NIS) gene expression in lymph-node metastases of papillary thyroid carcinomas. European Journal of Endocrinology 143 623-627. (doi:10.1530/eje.0.1430623)

Arturi F, Ferretti E, Presta I, Mattei T, Scipioni A, Scarpelli D, Bruno R, Lacroix L, Tosi E, Gulino A et al. 2005 Regulation of iodide uptake and sodium/iodide symporter expression in the MCF-7 human breast cancer cell line. Journal of Clinical Endocrinology and Metabolism 90 2321-2326. (doi:10.1210/jc.2004-1562)

Balasubramanian S, Verner E \& Buggy JJ 2009 Isoform-specific histone deacetylase inhibitors: the next step? Cancer Letters 280 211-221. (doi:10.1016/j.canlet.2009.02.013)

Batty N, Malouf GG \& Issa JP 2009 Histone deacetylase inhibitors as anti-neoplastic agents. Cancer Letters 280 192-200. (doi:10.1016/j. canlet.2009.03.013)

Cantley M, Fairlie D, Bartold P, Rainsford K, Le G, Lucke A, Holding C \& Haynes D 2011 Compounds that inhibit histone deacetylases in class I and class II effectively suppress human osteoclasts in vitro. Journal of Cellular Physiology 226 3233-3241. (doi:10.1002/jcp.22684)

Chang J, Varghese DS, Gillam MC, Peyton M, Modi B, Schiltz RL, Girard L \& Martinez ED 2012 Differential response of cancer cells to HDAC inhibitors trichostatin A and depsipeptide. British Journal of Cancer 106 116-125. (doi:10.1038/bjc.2011.532)

Dash PK, Orsi SA, Zhang M, Grill RJ, Pati S, Zhao J \& Moore AN 2010 Valproate administered after traumatic brain injury provides neuroprotection and improves cognitive function in rats. PLoS ONE 5 e11383. (doi:10.1371/journal.pone.0011383)
De La Vieja A, Dohan O, Levy O \& Carrasco N 2000 Molecular analysis of the sodium/iodide symporter: impact on thyroid and extrathyroid pathophysiology. Physiological Reviews 80 1083-1105.

Dohán O \& Carrasco N 2003 Advances in $\mathrm{Na}(+) / \mathrm{I}(-)$ symporter (NIS) research in the thyroid and beyond. Molecular and Cellular Endocrinology 213 59-70. (doi:10.1016/j.mce.2003.10.059)

Dohán O, Baloch Z, Bánrévi Z, Livolsi V \& Carrasco N 2001 Rapid communication: predominant intracellular overexpression of the $\mathrm{Na}(+) / \mathrm{I}(-)$ symporter (NIS) in a large sampling of thyroid cancer cases. Journal of Clinical Endocrinology and Metabolism 86 2697-2700. (doi:10.1210/jc.86.6.2697)

Duenas-Gonzalez A, Candelaria M, Perez-Plascencia C, Perez-Cardenas E, de la Cruz-Hernandez E \& Herrera LA 2008 Valproic acid as epigenetic cancer drug: preclinical, clinical and transcriptional effects on solid tumors. Cancer Treatment Reviews 34 206-222. (doi:10.1016/ j.ctrv.2007.11.003)

Fenton MS, Marion KM \& Hershman JM 2008 Identification of cyclic adenosine $3^{\prime}, 5^{\prime}$-monophosphate response element modulator as an activator of the human sodium/iodide symporter upstream enhancer. Endocrinology 149 2592-2606. (doi:10.1210/en.20071390)

Fritzsche FR, Weichert W, Röske A, Gekeler V, Beckers T, Stephan C, Jung K, Scholman K, Denkert C, Dietel M et al. 2008 Class I histone deacetylases 1, 2 and 3 are highly expressed in renal cell cancer. BMC Cancer 8 381. (doi:10.1186/1471-2407-8-381)

Furuya F, Shimura H, Suzuki H, Taki K, Ohta K, Haraguchi K, Onaya T, Endo T \& Kobayashi T 2004 Histone deacetylase inhibitors restore radioiodide uptake and retention in poorly differentiated and anaplastic thyroid cancer cells by expression of the sodium/iodide symporter thyroperoxidase and thyroglobulin. Endocrinology 145 2865-2875. (doi:10.1210/en.2003-1258)

Gallinari P, Di Marco S, Jones P, Pallaoro M \& Steinkühler C 2007 HDACs histone deacetylation and gene transcription: from molecular biology to cancer therapeutics. Cellular Research 17 195-211. (doi:10.1038/sj.cr.7310149)

Hingorani M, Spitzweg C, Vassaux G, Newbold K, Melcher A, Pandha H, Vile R \& Harrington K 2010 The biology of the sodium iodide symporter and its potential for targeted gene delivery. Current Cancer Drug Targets 10 242-267. (doi:10.2174/15680091079 1054194)

Hou P, Bojdani E \& Xing M 2010 Induction of thyroid gene expression and radioiodine uptake in thyroid cancer cells by targeting major signaling pathways. Journal of Clinical Endocrinology and Metabolism 95 820-828. (doi:10.1210/jc.2009-1888)

Huang PH, Chen CH, Chou CC, Sargeant AM, Kulp SK, Teng CM, Byrd JC \& Chen CS 2011 Histone deacetylase inhibitors stimulate histone $\mathrm{H} 3$ lysine 4 methylation in part via transcriptional repression of histone H3 lysine 4 demethylases. Molecular Pharmacology 79 197-206. (doi:10.1124/mol.110.067702)

Kitazono M, Robey R, Zhan Z, Sarlis NJ, Skarulis MC, Aikou T, Bates S \& Fojo T 2001 Low concentrations of the histone deacetylase inhibitor, depsipeptide (FR901228), increase expression of the $\mathrm{Na}(+) / \mathrm{I}(-)$ symporter and iodine accumulation in poorly differentiated thyroid carcinoma cells. Journal of Clinical Endocrinology and Metabolism 86 3430-3435. (doi:10.1210/jc.86.7.3430)

Kogai T, Taki K \& Brent GA 2006 Enhancement of sodium/iodide symporter expression in thyroid and breast cancer. Endocrine-Related Cancer 13 797-826. (doi:10.1677/erc.1.01143)

Krämer OH, Zhu P, Ostendorff HP, Golebiewski M, Tiefenbach J, Peters MA, Brill B, Groner B, Bach I, Heinzel T et al. 2003 The histone deacetylase inhibitor valproic acid selectively induces proteasomal degradation of HDAC2. EMBO Journal 22 3411-3420. (doi:10.1093/emboj/cdg315)

Kristensen LS, Nielsen HM \& Hansen LL 2009 Epigenetics and cancer treatment. European Journal of Pharmacology 625 131-142. (doi:10.1016/j.ejphar.2009.10.011)

Lazar V, Bidart JM, Caillou B, Mahé C, Lacroix L, Filetti S \& Schlumberger M 1999 Expression of the $\mathrm{Na}+/ \mathrm{I}-$ symporter gene 
in human thyroid tumors: a comparison study with other thyroid-specific genes. Journal of Clinical Endocrinology and Metabolism 84 3228-3234. (doi:10.1210/jc.84.9.3228)

Lehrmann H, Pritchard LL \& Harel-Bellank A 2002 Histone acetyltransferases and deacetylases in the control of cell proliferation and differentiation. Advances in Cancer Research 86 41-65. (doi:10.1016/S0065-230X (02)86002-X)

Lin X, Ryu KY \& Jhiang SM 2004 Cloning of the $5^{\prime}$-flanking region of mouse sodium/iodide symporter and identification of a thyroid-specific and TSH-responsive enhancer. Thyroid 14 19-27. (doi:10.1089/105072504322783803)

Marks PA \& Xu WS 2009 Histone deacetylase inhibitors: potential in cancer therapy. Journal of Cellular Biochemistry 107 600-608. (doi:10.1002/jcb.22185)

Nakagawa M, Oda Y, Eguchi T, Aishima S, Yao T, Hosoi F, Basaki Y, Ono M, Kuwano M, anaka M et al. 2007 Expression profile of class I histone deacetylases in human cancer tissues. Oncology Reports 18 769-774.

Nightingale KP, Gendreizig S, White DA, Bradbury C, Hollfelder F \& Turner BM 2007 Cross-talk between histone modifications in response to histone deacetylase inhibitors: MLL4 links histone H3 acetylation and histone H3K4 methylation. Journal of Biological Chemistry 282 4408-4416. (doi:10.1074/jbc.M606773200)

Ohno M, Zannini M, Levy O, Carrasco N \& Di Lauro R 1999 The paired-domain transcription factor Pax8 binds to the upstream enhancer of the rat sodium/iodide symporter gene and participates in both thyroid-specific and cyclic-AMP-dependent transcription. Molecular and Cellular Biology 19 2051-2060.

Puppin C, D'Aurizio F, D'Elia AV, Cesaratto L, Tell G, Russo D, Filetti S, Ferretti E, Tosi E, Mattei T et al. 2005 Effects of histone acetylation on sodium iodide symporter promoter and expression of thyroidspecific transcription factors. Endocrinology 146 3967-3974. (doi:10.1210/en.2005-0128)

Rando OJ 2007 Global patterns of histone modifications. Current Opinion in Genetics and Development 17 94-99. (doi:10.1016/j.gde. 2007.02.006)

Riedel C, Dohán O, De la Vieja A, Ginter CS \& Carrasco N 2001 Journey of the iodide transporter NIS: from its molecular identification to its clinical role in cancer. Trends in Biochemical Sciences 26 490-496. (doi:10.1016/S0968-0004(01)01904-1)

Riesco-Eizaguirre G, Rodríguez I, De la Vieja A, Costamagna E, Carrasco N, Nistal M \& Santisteban P 2009 The BRAFV600E oncogene induces transforming growth factor beta secretion leading to sodium iodide symporter repression and increased malignancy in thyroid cancer. Cancer Research 69 8317-8325. (doi:10.1158/0008-5472.CAN-09-1248)

Rosenberg G 2007 The mechanisms of action of valproate in neuropsychiatric disorders: can we see the forest for the trees? Cellular and Molecular Life Sciences 64 2090-2103. (doi:10.1007) s00018-007-7079-x)

Russo D, Damante G, Puxeddu E, Durante C \& Filetti S 2011 Epigenetics of thyroid cancer and novel therapeutic targets. Journal of Molecular Endocrinology 46 R73-R81. (doi:10.1530/ JME-10-0150)

Ruthenburg AJ, Allis CD \& Wysocka J 2007 Methylation of lysine 4 on histone H3: intricacy of writing and reading a single epigenetic mark. Molecular Cell 25 15-30. (doi:10.1016/j.molcel.2006.12.014)

Samuni Y, Flores-Santana W, Krishna MC, Mitchell JB \& Wink DA 2009 The inhibitors of histone deacetylase suberoylanilide hydroxamate and trichostatin A release nitric oxide upon oxidation. Free Radical Biology E Medicine 47 419-423. (doi:10.1016/j.freeradbiomed. 2009.05.011)

Santos-Rosa H, Schneider R, Bannister AJ, Sherriff J, Bernstein BE, Emre NC, Schreiber SL, Mellor J \& Kouzarides T 2002 Active genes are tri-methylated at K4 of histone H3. Nature 419 407-411. (doi:10.1038/nature01080)

Schlumberger M, Lacroix L, Russo D, Filetti S \& Bidart JM 2007 Defects in iodide metabolism in thyroid cancer and implications for the follow-up and treatment of patients. Nature Clinical Practice. Endocrinology and Metabolism 3 260-269. (doi:10.1038/ ncpendmet0449)

Schmitt TL, Espinoza CR \& Loos U 2001 Transcriptional regulation of the human sodium/iodide symporter gene by Pax8 and TTF-1. Experimental and Clinical Endocrinology E Diabetes 109 27-31. (doi:10.1055/s-2001-11016)

Schweppe RE, Klopper JP, Korch C, Pugazhenthi U, Benezra M, Knauf JA, Fagin JA, Marlow LA, Copland JA, Smallridge RC et al. 2008 Deoxyribonucleic acid profiling analysis of 40 human thyroid cancer cell lines reveals cross-contamination resulting in cell line redundancy and misidentification. Journal of Clinical Endocrinology and Metabolism 93 4331-4341. (doi:10.1210/ jc.2008-1102)

Shahbazian MD \& Grunstein M 2007 Functions of site-specific histone acetylation and deacetylation. Annual Reviews in Biochemistry 76 75-100. (doi:10.1146/annurev.biochem.76.052705. 162114)

Sodré AK, Rubio IG, Galrão AL, Knobel M, Tomimori EK, Alves VA, Kanamura CT, Buchpiguel CA, Watanabe T, Friguglietti CU et al. 2008 Association of low sodiumiodide symporter messenger ribonucleic acid expression in malignant thyroid nodules with increate intracellular protein staining. Journal of Clinical Endocrinology and Metabolism 93 4141-4145. (doi:10.1210/jc.2007-0353)

Struhl K 1998 Histone acetylation and transcriptional regulatory mechanisms. Genes and Development 12 599-606. (doi:10.1101/gad. 12.5.599)

Suzuki J, Chen YY, Scott GK, Devries S, Chin K, Benz CC, Waldman FM \& Hwang ES 2009 Protein acetylation and histone deacetylase expression associated with malignant breast cancer progression. Clinical Cancer Research 15 3163-3171. (doi:10.1158/1078-0432. CCR-08-2319)

Taki K, Kogai T, Kanamoto Y, Hershman JM \& Brent GA 2002 A thyroid-specific far-upstream enhancer in the human sodium/ iodide symporter gene requires Pax- 8 binding and cyclic adenosine $3^{\prime}, 5^{\prime}$-monophosphate response element-like sequence binding proteins for full activity and is differentially regulated in normal and thyroid cancer cells. Molecular Endocrinology 16 2266-2282. (doi:10.1210/me.2002-0109)

Tan J, Cang S, Ma Y, Petrillo RL \& Liu D 2010 Novel histone deacetylase inhibitors in clinical trials as anti-cancer agents. Journal of Hematological Oncology 3 5. (doi:10.1186/1756-8722-3-5)

Tell G, Pellizzari L, Cimarosti D, Pucillo C \& Damante G 1998 Ref-1 controls pax-8 DNA-binding activity. Biochemical and Biophysical Research Communications 252 178-183. (doi:10.1006/bbrc. 1998.9548)

Trapasso F, Iuliano R, Chiefari E, Arturi F, Stella A, Filetti S, Fusco A \& Russo D 1999 Iodide symporter gene expression in normal and transformed rat thyroid cells. European Journal of Endocrinology 140 447-451. (doi:10.1530/eje.0.1400447)

Weichert W, Röske A, Gekeler V, Beckers T, Stephan C, Jung K, Fritzsche FR, Niesporek S, Denkert C, Dietel M et al. 2008a Histone deacetylases 1, 2 and 3 are highly expressed in prostate cancer and HDAC2 expression is associated with shorter PSA relapse time after radical prostatectomy. British Journal of Cancer 98 604-610. (doi:10.1038/sj.bjc.6604199)

Weichert W, Röske A, Niesporek S, Noske A, Buckendahl AC, Dietel M, Gekeler V, Boehm M, Beckers T \& Denkert C 2008b Class I histone deacetylase expression has independent prognostic impact in human colorectal cancer: specific role of class I histone deacetylases in vitro and in vivo. Clinical Cancer Research 14 1669-1677. (doi:10.1158/1078-0432.CCR-07-0990)

Received in final form 20 February 2012

Accepted 21 March 2012

Made available online as an Accepted Preprint 21 March 2012 